\title{
METODOLOGIAS E CRIMINALIDADE VIOLENTA NO BRASIL
}

\author{
Betânia Totino Peixoto \\ Renato SÉrgio de Lima \\ Marcelo Ottoni Durante
}

\begin{abstract}
Resumo: Este artigo desenvolve uma discussão metodológica sobre análises da distribuição espacial e temporal da criminalidade. A partir de metodologia originalmente construída na Fundação Seade, faz-se um debate sobre a não pertinência do ranqueamento de crimes e cidades e defendem-se análises que focam a intensidade e o comportamento evolutivo da criminalidade no tempo e no espaço.

Palavras-chave: estatísticas criminais; crimes violentos; violência no Brasil.

Abstract: This article takes a methodological approach to the spatial and chronological analysis of criminality. Based on the methodology developed by Fundação Seade, the relevance of the ranking of crimes and cities is debated, and a case is made for a method of analysis that focuses on the intensity and the evolution of criminal behavior over time and space.

Key words: crime statistics; violent crimes; violence in Brazil.
\end{abstract}

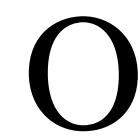
s estudos sobre crime e violência no Brasil ganharam fôlego a partir dos anos 70 e, desde então, sofisticaram o debate sobre os significados e sentidos que tais conceitos têm assumido na nossa sociedade. Ao longo dos últimos 30 anos, ambos os conceitos passaram a comportar múltiplas interpretações e, por conseguinte, impuseram um desafio complementar àqueles que produzem estatísticas e indicadores sociais e, em especial, aos que têm como atividade profissional consolidar e/ou descrever tendências e movimentos da criminalidade, sejam institutos de pesquisa, instituições nacionais e/ou regionais de estatísticas ou órgãos governamentais.

O desafio posto é consolidar um acervo mínimo de informações, com base em critérios, padrões e linguagens de fácil compreensão e utilização. Afinal, agregados estatísticos constituem um dos modos de compreender e controlar as populações e, como afirma Haggerty (2000: 5), são condições-chave para a possibilidade de governança e também funcionam como forma de produção de subjetividades (Haggerty, 2000:48). Isso significa dizer, portanto, que as estatísticas não são desprovidas de ideologia e retroalimentam o funcionamento e os interesses da burocracia de Estado, a qual, envolvida na produção das esta- tísticas, é uma das mais anônimas estruturas de Estado, além de ser quem determina não somente regras administrativas, mas classificações e critérios de seleção de prioridades de governo. O problema, portanto, seriam os parâmetros e os objetivos por detrás das classificações que, no limite, traduziriam a gramática e a linguagem do poder (Hacking, 1991).

É neste contexto que o debate sobre metodologias de análise espacial e temporal da criminalidade, principalmente nas suas modalidades violentas, ganha corpo e dá sentido aos objetivos deste artigo, na medida em que crime e violência manifestam-se como fenômenos altamente correlacionados com as dimensões espaço e tempo. Assim, ao se propor uma metodologia de análise da criminalidade violenta no país, preocupa-se, na realidade, em construir indicadores sociais sensíveis o suficiente para, ao mesmo tempo, indicar o movimento e a tendência da violência e identificar o resultado da ação do Estado numa área hoje particularmente crítica da nossa sociedade.

Em outras palavras, a proposta é pensar uma metodologia que descreva as diferenças regionais do crime $\mathrm{e}$ da violência e, ainda, descreva/identifique o impacto das políticas públicas até então empreendidas. Do contrário, 
a construção de indicadores e estatísticas pode, muito provavelmente, cair em armadilhas organizacionais que impeçam sua incorporação como ferramentas de planejamento de políticas públicas. Muitas das políticas públicas iniciadas nesta área dependem de um longo tempo de maturação, e uma simples avaliação da tendência dos crimes pouco avança na compreensão daquilo que pode ou que deve ser conduzido para reduzir o impacto do crime violento na sociedade brasileira. Apresentar o ranking dos crimes e das Unidades da Federação pouco acrescenta ao debate público hoje existente e pode reificar estigmas e preconceitos, até mesmo com impactos econômicos.

Por detrás de um método bastante simples está o pressuposto político de que transformações no modelo de gestão da segurança pública e impactos nas tendências da criminalidade violenta no país somente serão viáveis com a circunscrição o mais precisamente possível das competências, responsabilidades e resultados das políticas empreendidas. Polícia e Justiça, portanto, não são o resultado apenas de práticas jurídicas e/ou técnicas e dependem fortemente de enfoques multidisciplinares (Lima, 2003).

Para além da construção de indicadores, defende-se a incorporação da avaliação como pressuposto de políticas públicas. Com indicadores sensíveis e práticas de avaliação disseminadas, a possibilidade de aumento de eficiência da política é uma realidade concreta. Trata-se de superar o empiricismo e avançar na articulação de novos procedimentos de gestão e integração de ações, muito mais poderosos do que alterações legislativas casuísticas e pautadas pela vontade de vingança despertada pela sensação de medo, insegurança e impunidade que é observada no país.

Por mais que a estrutura normativa seja passível de críticas, crime e violência podem ser imediatamente combatidos com investimentos na reestruturação da gestão das instituições de Justiça Criminal do Brasil. Polícias Civil e Militar, Ministérios Públicos, Poder Judiciário, Sistema Carcerário e, mais recentemente incluídas no rol de instituições de segurança, as Guardas Municipais ainda funcionam de forma pouco eficiente. Novas tecnologias e métodos de administração, quando incorporados, não são capazes de alterar procedimentos, processos e fluxos, quase sempre justificados no rigor da técnica jurídica, mas muitas vezes criados na lógica da reprodução burocrática de práticas passadas. É verdade que nos últimos anos uma série de medidas tem sido adotada para alterar este quadro e que muitas delas possuem níveis considerados de sucesso. Até por isso, reconhece-se que o desafio é gran- de e que a contribuição deste artigo é bastante circunscrita a uma esfera dos inúmeros problemas relacionados aos fenômenos do crime e da violência.

No limite, o objetivo aqui é ampliar a discussão sobre transparência, acessibilidade e qualidade dos dados criminais existentes no país. Para tanto, considerou-se que, no monitoramento das tendências temporais e espaciais da criminalidade violenta, uma nova forma de visualização dos problemas se coloca. Em vez do tradicional "ranqueamento" de cidades e/ou Unidades da Federação, ou seja, listá-las por ordem de colocação, propõe-se um outro enfoque, que considera os patamares e volumes de registros e também identifica se determinado tipo/padrão de crime violento está apresentando um comportamento crescente ou decrescente em relação à sua notificação.

Isso é importante para avaliar esforços que possam estar sendo feitos e que ainda não tenham conseguido alterar a posição de uma ou outra unidade da federação no ranking, mas que são fundamentais e devem ser incentivados. Do contrário, a cada divulgação, novas ações podem vir a ser planejadas e implantadas sem o devido conhecimento do fenômeno, gerando descontinuidades, fragmentação das políticas e baixa efetividade da ação pública.

Diante destes objetivos, o desafio foi pensar em como poder-se-ia apresentar, de forma bastante simples e clara, a evolução dos registros policiais e avaliar a distribuição espacial da criminalidade. Para tanto, utilizou-se metodologia desenvolvida originalmente na Fundação Seade (2001) para avaliar, exatamente, a distribuição espacial de crimes no Estado de São Paulo e foram feitas adaptações para torná-la mais sensível às pequenas oscilações na incidência da criminalidade. Com isso, foi possível identificar, além do volume de registros de crimes violentos, o nível de oscilação que a intensidade deste fenômeno vem apresentando ao longo dos anos.

A diferença em relação à metodologia original, como já foi dito, é que agora pode-se mensurar a intensidade do crescimento ou da redução das taxas de ocorrências policiais por $100 \mathrm{mil}$ habitantes. Seja como for, para descrever as etapas e procedimentos, apresentam-se a seguir, o detalhamento desta metodologia e uma aplicação prática na divulgação do panorama da violência no Brasil, sob responsabilidade da Secretaria Nacional de Segurança Pública, que assumiu esta nova forma de apresentar os dados, aumentando, assim, a compreensão sobre problema tão candente hoje no país. Na prática, propõemse abordagens inovadoras de registros administrativos, 
muitas vezes esquecidos pelas Instituições Estatísticas devido aos custos de seu tratamento e/ou em razão de decisões que priorizam outras formas de coleta de dados.

O exercício a seguir é apenas um pequeno exemplo do potencial que o uso de informações criminais possui.

\section{METODOLOGIA}

A metodologia proposta por este trabalho é bastante simples e consiste em técnica de análise dos dados criminais, considerando-se as dimensões espacial e temporal do fenômeno. A primeira é contemplada na comparação do fenômeno ocorrido na região territorial de análise com o fenômeno vigente em todo o território, enquanto a temporal é considerada quando se analisa o fenômeno em vários períodos temporais e sua taxa de crescimento. Assim, a sofisticação é possível com a sobreposição de análises que, da forma tradicional, seriam feitas separadamente e nem sempre relacionadas entre si.

O método consiste em, primeiramente, fazer uma média da taxa de crime por 100 mil habitantes ${ }^{1}$ nos períodos de tempo considerados para cada região:

$$
\text { Média }_{R}=\frac{\sum_{1}^{n}\left(\text { txcrime }_{i}\right)}{n}
$$

onde:

txcrime é a taxa de crime por 100 mil habitantes;

$\mathrm{R}$ é a região territorial;

i são os períodos de tempo;

$n$ é o número de períodos.

Além da taxa de crime por 100 mil habitantes média dos períodos de tempo para cada região, calcula-se a taxa de crescimento desta no período total:

$$
\text { cres }_{R}=\frac{\left(\text { txcrime }_{n}-\text { txcrime }_{1}\right)}{\text { txcrime }_{1}}
$$

Em seguida, é calculada a média do território através da variável Média ${ }_{R}$ :

$$
\text { MédiaT }=\frac{\sum_{1}^{r}\left(\text { Média }_{R}\right)}{r}
$$

onde:

Média $a_{R}$ é a média da taxa de crime por 100 mil habitantes nos períodos de tempo;

$\mathrm{T}$ indica todo o território;

$\mathrm{R}$ são as regiões territoriais;

r é o número de regiões.

Após os cálculos, dividem-se as regiões em dois clusters (grupos) de análise por meio da comparação da taxa de crime por 100 mil habitantes média de cada região $\left(\right.$ Média $\left._{R}\right)$ com aquela referente ao total do território $\left(\right.$ Média ${ }_{T}$ ), usando o seguinte critério:

Se $M e ́ d i a_{R}>$ MédiaT então a região é do cluster "acima da média".

Se $M e ́ d i a_{R}<$ MédiaT então a região é do cluster "abaixo da média”.

Feita a separação das regiões por clusters, utiliza-se a taxa de crescimento $\left(\right.$ cres $_{R}$ ) para construção do mapa temático, que é elaborado conjuntamente para os dois clusters, considerando faixas de taxa de crescimento obtidas de acordo com a análise de sua distribuição. Para melhor visualização, subdividem-se dentro de cada cluster as regiões em que a taxa de crescimento é maior que zero (a taxa de crime por 100 mil habitantes cresceu no período) e aquelas em que essa taxa é menor que zero (a taxa de crime por 100 mil habitantes decresceu no período).

Desta forma, a visualização final da metodologia é um mapa temático que combina a posição da taxa de crime por 100 mil habitantes média da região em relação à do território total com a taxa de crescimento desta no período.

A aplicação desta metodologia utilizou, como unidade de análise espacial, os Estados brasileiros e, como dimensão temporal, os cinco semestres compreendidos entre janeiro de 2001 e junho de 2003. Como taxa de criminalidade, usaram-se os indicadores criados pela Secretaria Nacional de Segurança Publica - Senasp, que dividem as ocorrências de crimes violentos intencionais registradas pelas Polícias Civis das Unidades da Federação em: crimes letais intencionais; crimes violentos não letais contra a pessoa; e crimes violentos contra o patrimônio. Além disso, apresenta-se uma análise da razão entre população e total de efetivo das Polícias Militar e Civil com o intuito de ilustrar a utilização da metodologia em outros fenômenos que não a criminalidade. Os resultados serão exibidos na próxima seção. 


\section{PANORAMA DA VIOLÊNCIA NO BRASIL}

Como aplicação metodológica, mostra-se a seguir um panorama da violência no Brasil a partir do volume de ocorrências policiais registrados entre o primeiro semestre de 2001 e o primeiro semestre de 2003. Contudo, cabe destacar que o crescimento da criminalidade, observado a partir das estatísticas oficiais, pode estar refletindo uma série de outros fenômenos que não o efetivo aumento da incidência destes crimes específicos. Vale lembrar que, como fontes de informação, dados estatísticos, em sua maioria produzidos pelo Estado, implicam necessariamente a contextualização dos resultados obtidos, tal como já foi enunciado anteriormente.

Neste contexto, emerge entre os desafios postos ao desenho de uma política abrangente de segurança pública a dificuldade em se dispor de informações quantitativas e qualitativas de qualidade, passíveis de serem incorporadas como ferramentas de planejamento de políticas públicas. Não obstante algumas iniciativas locais que vêm sendo adotadas nos Estados e pelo Ministério da Justiça, é possível afirmar que ainda não existe uma política de integração de informações em justiça criminal e segurança pública.

O Ministério da Justiça, por meio da Secretaria Nacional de Segurança Pública, tem investido esforços e recursos na política de aprimoramento do tratamento e gestão da informação pelas organizações policiais federais, estaduais e municipais. Exemplo desta ação foi o lançamento, em dezembro de 2003, do primeiro módulo do Sistema Nacional de Estatísticas de Segurança Pública e Justiça Criminal, que envolveu diversas etapas fundamentais para a padronização dos procedimentos de tratamento da informação: construção de um sistema de compatibilização das 54 formas de classificação das ocorrências policiais utilizadas pelas organizações policiais militares e civis estaduais; realização de um diagnóstico amplo dos objetivos atribuídos pelo público à constituição do sistema; difusão de uma política de valorização dos mecanismos de gestão do conhecimento e da informação; e definição de uma política clara de relação entre o público interno e o externo das organizações policiais.

Estas iniciativas são fundamentais para a incorporação da informação como ferramenta de ação, mas ainda dependem da articulação de esforços interinstitucionais, não sendo possível, neste momento, extrair dados e informações já neste formato de produção e uso. Entretanto, a aplicação da metodologia aqui apresentada toma por base os dados já disponíveis e, como será visto a seguir, per- mite destaques e notas sobre o que o senso comum imagina como a realidade da violência no Brasil.

No Mapa 1 visualizam-se dois aspectos específicos: a posição do Estado em relação à incidência nacional do fenômeno e sua situação quanto ao comportamento crescente ou decrescente da taxa de incidência.

Verifica-se que, das 27 Unidades da Federação, 15 apresentam taxas de registro de crimes letais intencionais abaixo da média ponderada nacional e 12 registram valores acima desta média. Entre os Estados com taxas inferiores à média nacional, Pará, Rio Grande do Sul, Roraima, Mato Grosso, Tocantins, Piauí e Paraná tiveram decréscimo da taxa no período. Daqueles que exibiram taxas acima da média brasileira, Rondônia, Mato Grosso do Sul, São Paulo, Espírito Santo e Distrito Federal apresentaram redução das taxas no período. Nas demais unidades, as taxas cresceram.

Na Região Norte, Amapá, Acre e Rondônia exibem taxas de crimes letais intencionais acima da média nacional, sendo que em Rondônia houve redução no período analisado, enquanto no Amapá e no Acre registrou-se aumento da taxa. Os demais Estados da Região Norte apresentaram taxas de crimes letais intencionais abaixo da média ponderada nacional e somente no Amazonas esta taxa cresceu no período analisado.

$\mathrm{Na}$ Região Nordeste também predominam os Estados com taxas abaixo da média nacional. Somente Pernambuco, Alagoas e Sergipe exibem taxas de crime letal intencional superiores à do país. Entretanto, em todos os Estados da região, exceto Piauí, a taxa de crime por 100 mil habitantes aumentou no período.

Ao contrário do Nordeste, na Região Centro-Oeste a predominância é de Estados com taxas de crimes letais intencionais acima da média ponderada nacional. Apesar disto, estas taxas diminuíram no período, com exceção de Goiás, onde verificou-se aumento. O Estado do Mato Grosso foi o único que exibiu taxas abaixo desta média.

Na Região Sudeste, apenas Minas Gerais apresentou taxas de crimes letais intencionais abaixo da média nacional, porém estas cresceram $25 \%$ no período. Já São Paulo e Espírito Santo, com taxas acima da média nacional, registram decréscimos de $1 \%$ a $15 \%$ no período. O estado do Rio de Janeiro além de estar acima da média nacional teve a taxa crescendo $14 \%$ no período.

Por fim, os três Estados da Região Sul tiveram taxas de crimes letais intencionais abaixo da média ponderada nacional. Além disso, no Rio Grande do Sul e, principal- 
mente, no Paraná verificou-se redução dos valores no período. Entretanto, em Santa Catarina houve crescimento das taxas no período.

Em relação à incidência de registros de crimes violentos não letais contra a pessoa, verifica-se que apenas seis Unidades da Federação possuem taxas superiores à média nacional: Minas Gerais, Mato Grosso do Sul, Bahia, São Paulo, Distrito Federal e Rio de Janeiro. Destes Estados, Mato Grosso do Sul e Minas Gerais se destacam pelo crescimento das taxas de registro destes delitos. Entre as
21 Unidades da Federação com taxas inferiores à nacional, cinco apresentaram redução da taxa (Ceará e Piauí, com decréscimo de $1 \%$ a $30 \%$ no período, e Roraima, Amazonas e Mato Grosso, com declínio superior a 30\%) e 16 estados registraram aumento (Acre, Rondônia, Amapá, Pará, Tocantins, Rio Grande do Norte, Paraíba, Alagoas, Espírito Santo, Santa Catarina e Rio Grande do Sul, com crescimento de $1 \%$ a $30 \%$ no período, e Maranhão, Pernambuco, Sergipe e Pará, com expansão acima de $30 \%$ ).

MAPA 1

Taxas de Crescimento dos Registros de Crimes Letais Intencionais Unidades da Federação - 2001-2003

Média Ponderada Nacional: 12,8 / Por 100 mil habitantes

\begin{tabular}{|c|c|}
\hline $\begin{array}{l}\text { Acima da média nacional e crescendo } \\
\text { acima de } 30 \% \text { no período }\end{array}$ & Alagoas e Sergipe \\
\hline $\begin{array}{l}\text { Acima da média nacional e crescendo } \\
\text { de } 5 \% \text { a } 30 \% \text { no período }\end{array}$ & $\begin{array}{l}\text { Acre, Amapá, Pernambuco, } \\
\text { Goiás, Rio de Janeiro }\end{array}$ \\
\hline $\begin{array}{l}\text { Acima da média nacional e decrescendo } \\
\text { de } 1 \% \text { a } 15 \% \text { no período }\end{array}$ & $\begin{array}{l}\text { Rondônia, Mato Grosso do Sul, São } \\
\text { Paulo, Espirito Santo, Distrito Federa }\end{array}$ \\
\hline $\begin{array}{l}\text { Abaixo da média nacional e crescendo } \\
\text { acima de } 25 \% \text { no período }\end{array}$ & $\begin{array}{l}\text { Maranhão, Paraíba, Minas Gerais, } \\
\text { Santa Catarina }\end{array}$ \\
\hline $\begin{array}{l}\text { Abaixo da média nacional e crescendo } \\
\text { de } 1 \% \text { a } 25 \% \text { no periodo }\end{array}$ & $\begin{array}{l}\text { Amazonas, Ceará, Rio Grande } \\
\text { do Norte, Bahia }\end{array}$ \\
\hline 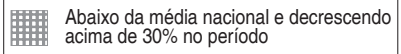 & Roraima, Mato Grosso, Paraná \\
\hline $\begin{array}{l}\text { Abaixo da média nacional e decrescendo } \\
\text { de } 1 \% \text { a } 30 \% \text { no período }\end{array}$ & $\begin{array}{l}\text { Pará, Tocantins, Rio Grande } \\
\text { do Sul }\end{array}$ \\
\hline Sem informação & Piauí \\
\hline
\end{tabular}

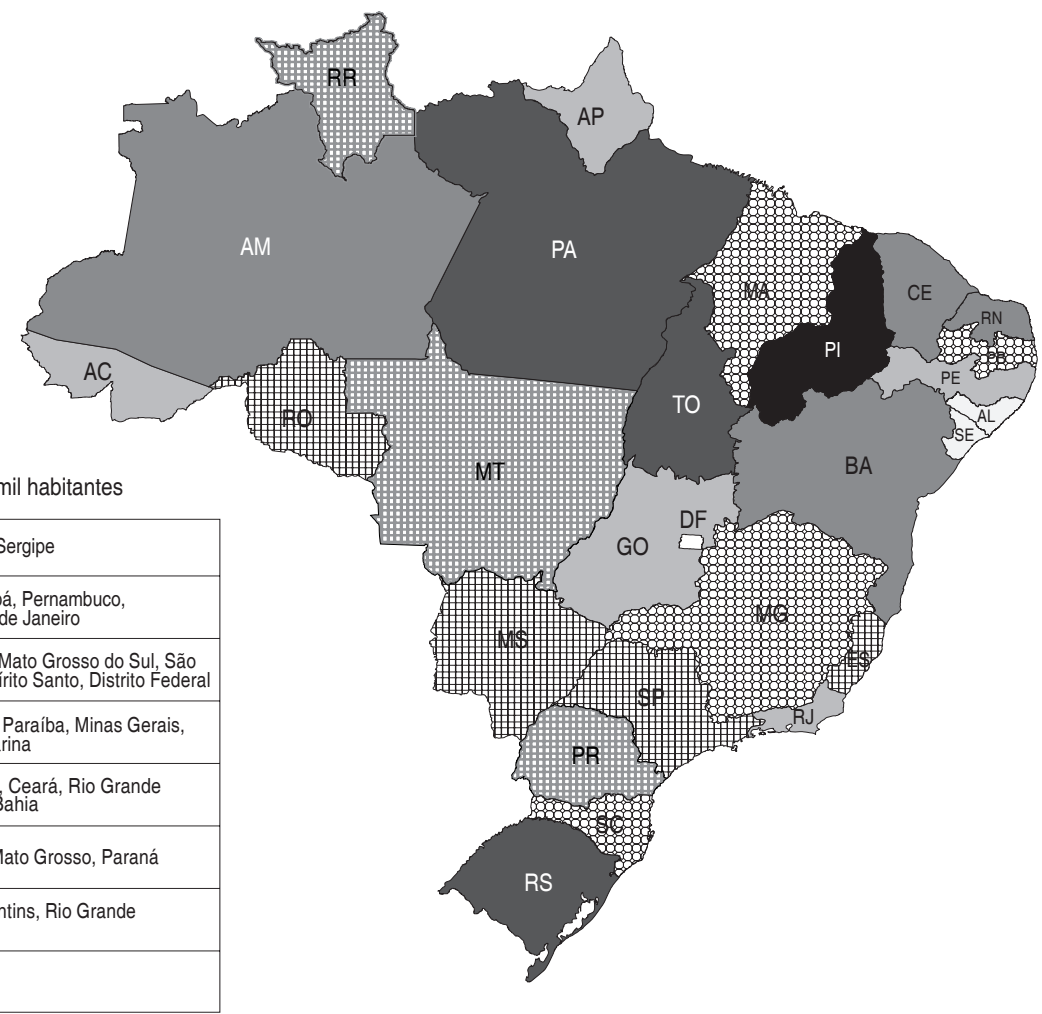

Fonte: Secretarias Estaduais de Segurança Pública; Secretaria Nacional de Segurança Pública - Senasp/Ministério da Justiça.

Todos os Estados da Região Norte exibiram taxas de crimes violentos não letais contra pessoa abaixo da média ponderada nacional. No Amazonas e em Roraima, estas decresceram mais de $30 \%$ no período, enquanto no Acre, Rondônia, Pará, Amapá e Tocantins aumentaram de $1 \%$ a $20 \%$.

$\mathrm{Na}$ Região Nordeste apenas a Bahia registrou taxas superiores à média nacional, porém estas reduziram-se no pe- ríodo. Rio Grande do Norte, Paraíba e Alagoas exibiram taxas que cresceram de $1 \%$ a $30 \%$ no período, assim como Maranhão, Pernambuco e Sergipe, cujo aumento foi superior a $30 \%$. Por fim, as taxas do Piauí e Ceará diminuíram no período.

Dos Estados da Região Centro-Oeste, Mato Grosso do Sul e o Distrito Federal apresentaram taxas acima da média nacional, mas só a do Mato Grosso do Sul aumentou 
no período, enquanto a do Distrito Federal diminuiu. Ao contrário, em Mato Grosso e Goiás verificaram-se taxas abaixo da média ponderada nacional: no primeiro esta taxa diminuiu e, no segundo, aumentou.

Na Região Sudeste, com exceção do Espírito Santo, todos os Estados apresentaram taxas de crimes violentos não letais contra a pessoa acima da média nacional, com redução de $1 \%$ a 5\%, em São Paulo, e acima de 20\%, no Espírito Santo. Em Minas Gerais esta taxa aumentou.

Todos os Estados da Região Sul registraram taxas de crimes violentos não letais contra a pessoa abaixo da média nacional e crescendo. Entretanto, as taxas do Paraná aumentaram mais no período do que as de Santa Catarina e Rio Grande do Sul.
Em relação à incidência de crimes violentos contra o patrimônio, verificou-se, assim como no caso dos crimes violentos não letais contra a pessoa, que a maior parte das Unidades da Federação possui taxas inferiores à média ponderada nacional, sendo que em apenas sete Estados estas taxas são superiores à média nacional (Pará, Goiás, Rio de Janeiro, Distrito Federal, São Paulo, Rio Grande do Sul e Rondônia). No entanto, destes sete Estados, apenas Rondônia vem apresentando comportamento de decréscimo de sua taxa.

$\mathrm{Na}$ Região Norte apenas os Estados de Rondônia e Pará apresentaram taxas de crimes violentos contra o patrimônio acima da média nacional, entretanto, a taxa do primeiro diminuiu e a do segundo aumentou no período.

MAPA 2

Média Ponderada Nacional: 71,3 / Por 100 mil habitantes

\begin{tabular}{|c|c|c|}
\hline & $\begin{array}{l}\text { Acima da média nacional e crescendo } \\
\text { acima de } 25 \% \text { no periodo }\end{array}$ & Minas Gerais e Mato Grosso do Sul \\
\hline & $\begin{array}{l}\text { Acima da média nacional e decrescendo } \\
\text { cerca de } 60 \% \text { no período }\end{array}$ & Rio de Janeiro \\
\hline 巴甩 & $\begin{array}{l}\text { Acima da média nacional e decrescendo } \\
\text { de } 1 \% \text { a } 25 \% \text { no período }\end{array}$ & Bahia, Distrito Federal e São Paulo \\
\hline 8 & $\begin{array}{l}\text { Abaixo da média nacional e crescendo } \\
\text { acima de } 30 \% \text { no período }\end{array}$ & $\begin{array}{l}\text { Maranhão, Pernambuco, Goiás, } \\
\text { Sergipe, Paraná }\end{array}$ \\
\hline & $\begin{array}{l}\text { Abaixo da média nacional e crescendo } \\
\text { de } 1 \% \text { a } 20 \% \text { no período }\end{array}$ & $\begin{array}{l}\text { Amapá, Pará, Rondônia, Acre, } \\
\text { Tocantins, Paraiba, Alagoas, Rio } \\
\text { Grande do Norte, Espirito Santo, } \\
\text { Santa Catarina e Rio Grande do Sul }\end{array}$ \\
\hline 曹 & $\begin{array}{l}\text { Abaixo da média nacional e decrescendo } \\
\text { acima de } 50 \% \text { no período }\end{array}$ & Amazonas, Roraima, Mato Grosso \\
\hline & $\begin{array}{l}\text { Abaixo da média nacional e decrescendo } \\
\text { até } 100 \% \text { no período }\end{array}$ & Ceará \\
\hline & Sem informação & Piauí \\
\hline
\end{tabular}

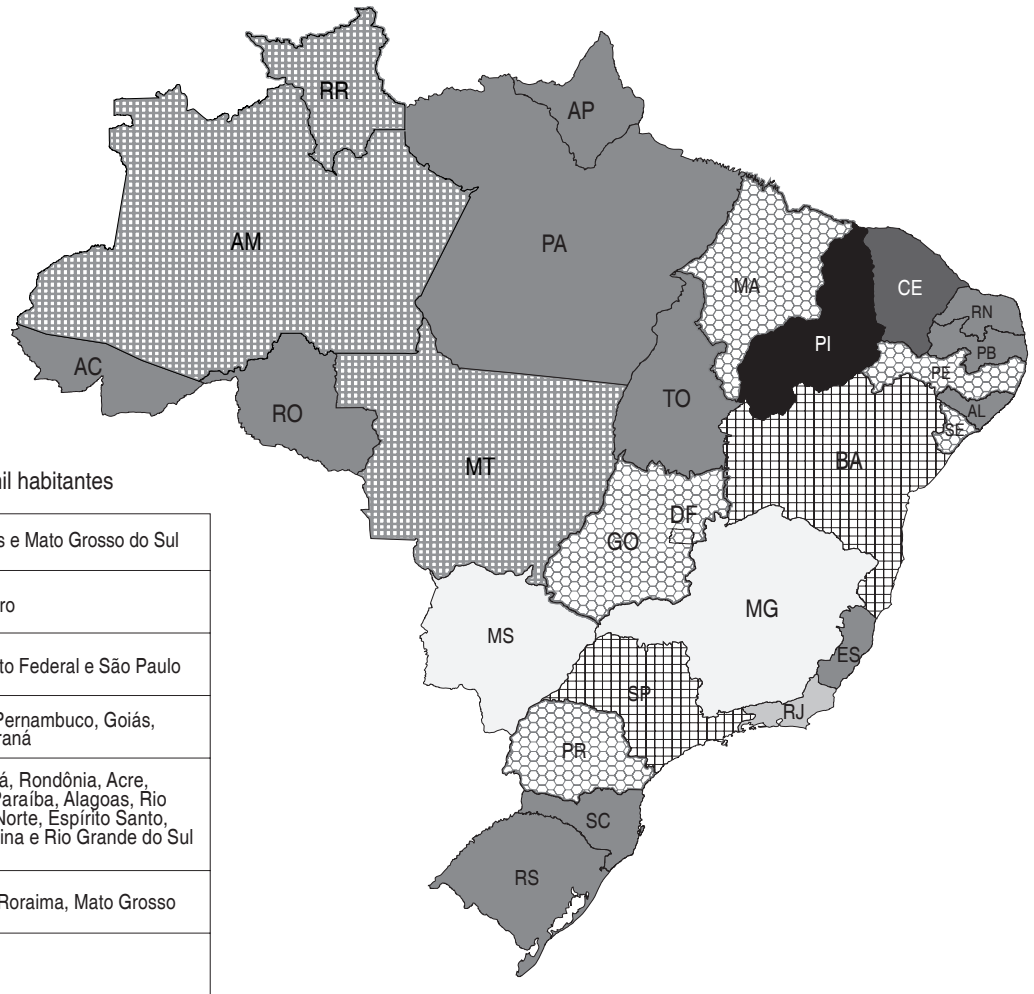

Fonte: Secretarias Estaduais de Segurança Pública; Secretaria Nacional de Segurança Pública - Senasp/Ministério da Justiça. 


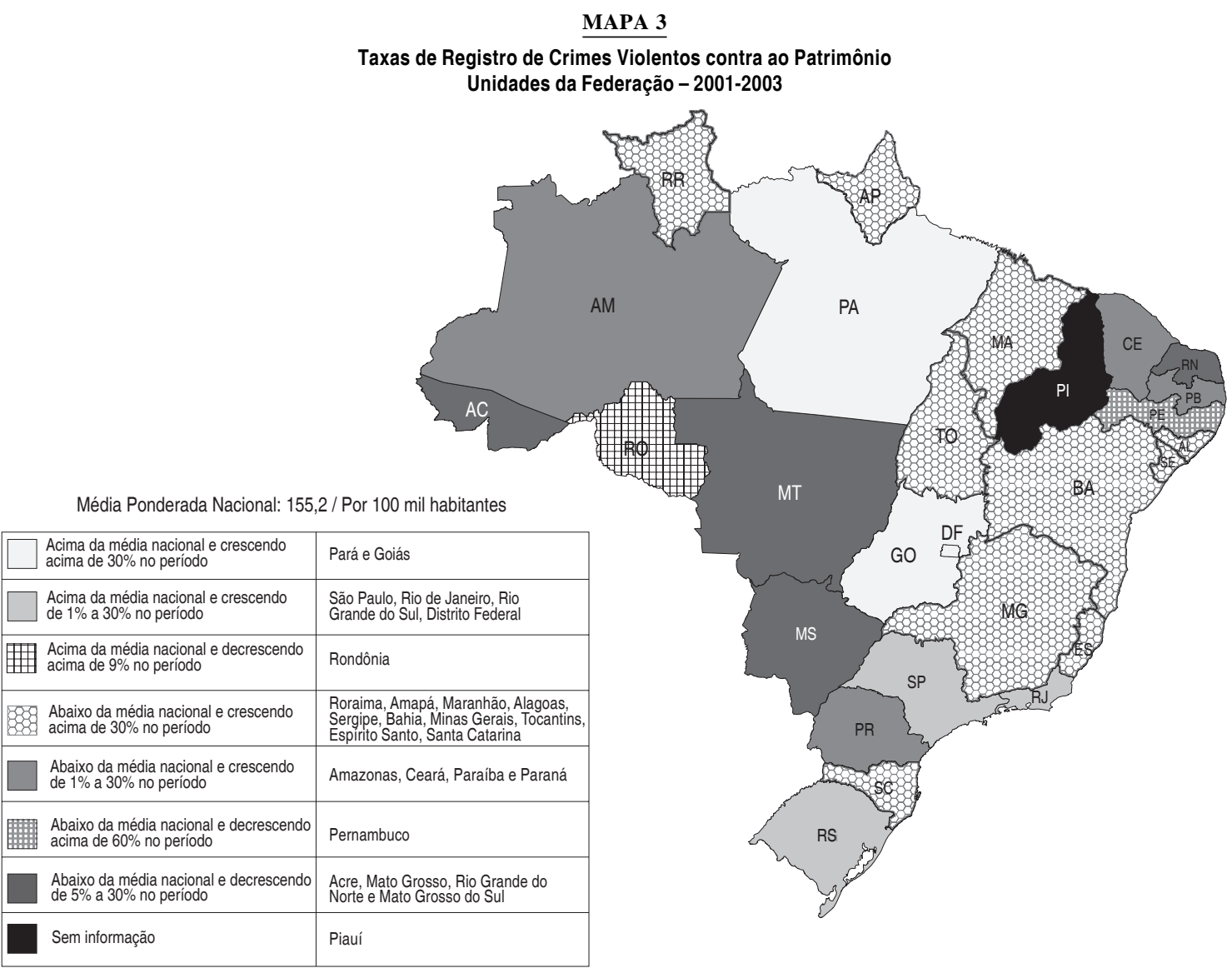

Fonte: Secretarias Estaduais de Segurança Pública; Secretaria Nacional de Segurança Pública - Senasp/Ministério da Justiça.

As taxas em Amazonas, Roraima, Amapá e Tocantins ficaram abaixo da média nacional e aumentaram no período, com crescimento de $1 \%$ a 50\% em Roraima e Amapá e acima de $50 \%$ no Amapá e Tocantins. Dos Estados que possuem taxas inferiores à média nacional, apenas o Acre registrou taxas de crime decrescentes.

Todos os Estados da Região Nordeste apresentaram taxas abaixo da média nacional. No Maranhão, Bahia, Sergipe, Alagoas, Paraíba e Ceará as taxas cresceram no período analisado, sendo que as do Maranhão e Alagoas aumentaram mais do que as dos outros Estados. Por outro lado, Piauí, Pernambuco e Rio Grande do Norte exibiram taxas decrescentes no período, principalmente nos dois primeiros.

Na Região Centro-Oeste, o Estado de Goiás e o Distrito Federal registraram taxas acima da média nacional e que cresceram no período analisado, com maior intensidade em Goiás. Mato Grosso e Mato Grosso do Sul tiveram taxas abaixo da média e que decresceram no período, principalmente no primeiro.
Todos os Estados da Região Sudeste apresentaram taxas de crimes violentos contra o patrimônio que cresceram no período analisado, entretanto, as de Minas Gerais e Espírito Santo estão abaixo da média nacional e as de São Paulo e Rio de Janeiro encontram-se acima. Na Região Sul, verificou-se comportamento semelhante ao dos Estados da Região Sudeste. Todos exibiram taxas de crimes violentos contra o patrimônio que cresceram no período analisado, ficando abaixo da média nacional no Paraná e em Santa Catarina e acima desse valor no Rio Grande do Sul.

Por fim, para ilustrar que esta metodologia também pode ser utilizada para mensurar outros fenômenos diferentes da incidência de registros criminais, realizou-se uma análise da razão entre população e total de efetivo entre as 27 Unidades da Federação. Sintetizando, o que se deseja é um número menor possível de pessoas por policial. Porém, esta análise deve ser considerada com muito cuidado, pois existem inúmeros fatores que afetam diretamente na eficiência e eficácia das organiza- 


\section{MAPA 4}

Comparativo do Comportamento da Razão entre População e Total de Efetivo das Polícias Civis e Militares Unidades da Federação - 2001-2003

Média Ponderada Nacional: 357,3 / Por 100 mil habitantes

\begin{tabular}{|l|l|}
\hline $\begin{array}{l}\text { Acima da média nacional e crescendo } \\
\text { de } 1 \% \text { a } 50 \% \text { no periodo }\end{array}$ & $\begin{array}{l}\text { Pará, Maranhão, Ceará, Piaúi, Minas } \\
\text { Gerais, Pernambuco, Paraná, Rio } \\
\text { Grande do Sul }\end{array}$ \\
\hline $\begin{array}{l}\text { Acima da média nacional e decrescendo } \\
\text { a } 16 \% \text { no periodo }\end{array}$ & Goiás \\
\hline $\begin{array}{l}\text { Acima da média nacional e decrescendo } \\
\text { de } 1 \% \text { a } 15 \% \text { no periodo }\end{array}$ & $\begin{array}{l}\text { Mato Grosso, Amazonas, Bahia e } \\
\text { Santa Catarina }\end{array}$ \\
\hline $\begin{array}{l}\text { Abaixo da média nacional e crescendo } \\
\text { de } 1 \% \text { a } 50 \% \text { no periodo }\end{array}$ & $\begin{array}{l}\text { Roraima, Rondônia, Acre, Tocantins, } \\
\text { Espírito Santo, Distrito Federal e } \\
\text { Mato Grosso do Sul }\end{array}$ \\
\hline $\begin{array}{l}\text { Abaixo da média nacional e decrescendo } \\
\text { de } 4 \% \text { a } 13 \% \text { no periodo }\end{array}$ & Amapá, Paraiba, Alagoas, Rio de Janeiro \\
\hline Sem informação & $\begin{array}{l}\text { Rio Grande do Norte, Sergipe e } \\
\text { São Paulo }\end{array}$ \\
\hline
\end{tabular}

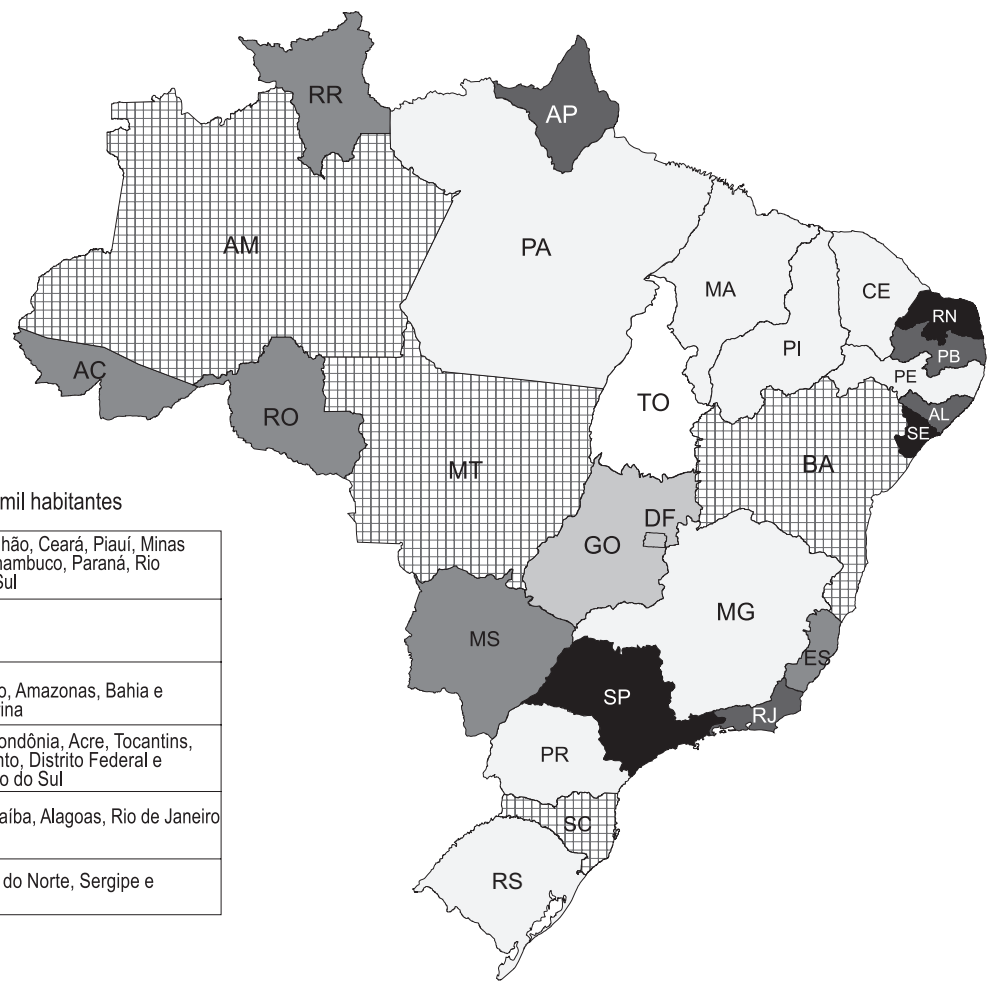

Fonte: Secretarias Estaduais de Segurança Pública; Secretaria Nacional de Segurança Pública - Senasp/Ministério da Justiça.

ções policiais na ação de combate à criminalidade, além do número de policiais. Assim, por exemplo, o nível tecnológico das organizações, a capacitação dos profissionais e o tipo de gestão que caracteriza as organizações policiais influenciam diretamente o resultado das ações das organizações policiais.

Existem treze Unidades da Federação que apresentam razões de população por efetivo superior à média ponderada nacional (Goiás, Amazonas, Mato Grosso, Bahia, Santa Catarina, Pará, Maranhão, Piauí, Ceará, Pernambuco, Minas Gerais, Paraná e Rio Grande do Sul). Deste conjunto, apenas quatro Estados estão melhorando sua situação e decrescendo o valor desta razão. Entre as Unidades da Federação que possuem razão de população por efetivo inferior à média nacional, quatro se destacam por apresentar ainda um decréscimo no valor destas razões, ou seja, uma redução do número de pessoas por policial (Amapá, Paraíba, Alagoas e Rio de Janeiro).

\section{CONCLUSÃO}

Pôde-se testar o potencial de utilização de uma metodologia bastante simples, mas que joga luz sobre uma série de problemas relacionados aos fenômenos do crime e da violência. Mais do que sofisticadas ferramentas e modelos, a produção de informações na área de justiça criminal e segurança pública carece de investimento na criação de uma política de tratamento e comunicação dos dados disponíveis. É óbvio que todos os instrumentos analíticos devem e podem ser usados, mas soluções simples e originais são importantes passos na transformação do modelo de gestão. Os resultados demonstram que os registros de crimes ainda possuem volumes elevados, mas, ao que tudo indica, não se pode dizer que existe um aumento generalizado do crime no Brasil. Várias Unidades da Federação, mesmo aquelas com taxas bem acima da média nacional, têm demonstrado capacidade de 
reação e provocado uma inflexão positiva nas tendências dos crimes violentos.

Se fosse considerado apenas o ranking dos crimes, não seria possível perceber esta reação e, portanto, os esforços poderiam estar sendo relegados - é verdade que, em alguns casos, os dados indicam que os esforços não têm sido capazes de reverter tendências crescentes dos crimes violentos. Enfim, os dados trazem, mesmo que indiretamente, informações sobre efetividade de políticas públicas. Com base neles, pode-se pensar em como a realidade exposta é fruto de ações de múltiplos atores e, uma vez identificados, apoiadas as suas boas práticas e iniciativas.

\section{NOTAS}

Agradecemos a atenção e o apoio de várias pessoas que permitiram a realização deste trabalho. São elas: Aurílio Sérgio Costa Caiado (que foi um dos que formularam a idéia original da metodologia aqui assumida), Lilian Liye Konishi e Eliana Bordini, da Fundação Seade; Equipe técnica do Departamento de Pesquisa, Análise da Informação e Desenvolvimento de Pessoal em Segurança Pública, da Senasp (Washington, Luiz Rubens, Matheus, Flavia Florêncio, Virginia da Rosa, Marcelle Figueira, Rafael, Vitor, Ana Paula Galdeano Cruz, Vânia Dias); e Luiz Henrique Proença Soares, do Ipea. Um agradecimento especial a Jacqueline Muniz, diretora da Senasp e incansável defensora de uma política pública transparente e fundada no compromisso com o interesse público.

1. Utilizou-se a taxa de crime por 100 mil habitantes por ser uma medida extensamente difundida na literatura internacional como a mais sensível na demonstração deste tipo de fenômeno. Entretanto, poderse-ia utilizar qualquer medida de criminalidade que possibilitasse a comparação dos crimes entre as regiões.

\section{REFERÊNCIAS BIBLIOGRÁFICAS}

FUNDAÇÃO SEADE. A violência e o seu impacto na sociedade paulista: uma análise a partir das estatísticas disponíveis na Fundação Seade. São Paulo, 2001. (Relatório de Pesquisa).

HACKING, I. How should we do the history of statistics? In: BURCHELL, G.; MILLER (Orgs.). The Foucault effect: studies in governmentality. Chicago: The University of Chicago Press, p. 181-196, 1991 .

HAGGERTY, K.D. Making crime count. University of Toronto Press, 2000.

LIMA, R.S. Valorização da produção e do uso de informações e estatísticas sobre segurança pública e justiça criminal no Brasil. Consultor Jurídico, 2003. Disponível em: <www.conjur.com.br〉.

Betânia Totino Peixoto: Pesquisadora do Crisp/UFMG. Consultora da Secretaria Nacional de Segurança Pública, do Ministério da Justiça.

Renato Sérgio de Lima: Sociólogo, Chefe da Divisão de Estudos Socioeconômicos da Fundação Seade.

Marcelo Ottoni Durante: Coordenador Geral de Pesquisa, da Secretária Nacional de Segurança, do Ministério da Justiça. 